\title{
ARTICLE
}

\section{Benchmark of PHITS for an absorbed dose rate evaluation from beta-radiation}

\author{
Fumiyoshi Nobuhara* and Shohei Iwai \\ Tokyo Nuclear Services Co. Ltd., 1-3-5 Taito, Taito-ku Tokyo, 110-0016, Japan
}

\begin{abstract}
After the TEPCO's Fukushima NPP Accident in 2011, it became necessary to evaluate the absorbed dose distant from beta emitting nuclides. We focused our attention on the beta sources $\left(\operatorname{such}\right.$ as $\left.{ }^{90} \mathrm{Sr} /{ }^{90} \mathrm{Y}\right)$ released in the accident. We try to perform benchmark analysis using PHITS code for the evaluation of the absorbed dose from beta radiation. The simulated absorbed dose rates for beta radiation by PHITS agreed with the measured absorbed dose rates to within $6 \%$ in the range from 1 to $1000 \mu \mathrm{m}$ deep in ICRU tissue. The PHITS code showed almost the same results as EGS5 code. The PHITS's ability to visualize with T-Deposit is useful and powerful to provide presentation Dose MAP from beta radiation.
\end{abstract}

Keywords: PHITS; beta emitter; absorbed dose; radiation field from beta radiation; ICRU tissue; benchmark

\section{Introduction}

A large amount of released radionuclides were deposited over wide areas in eastern Japan. The contaminated ground should be decontaminated by workers. The beta radiation from deposited nuclides on ground was not shielded for decontamination workers. In other place, a decontamination work is needed for high dose rate field in Fukushima NPP. In NPP contaminated water are stored in the tank and some operator should work near the non-shield contaminated water. Before the TEPCO's Fukushima NPP Accident in 2011, conservative rough dose evaluation was sufficient because these work is rare case. But at this time many workers exposure from non-shield situation. The rough dose estimation is denied because expert workers works long as much as possible. Then after the accident, it became necessary to more accurately evaluate the absorbed dose distant from deposited beta nuclides. We focused our attention on the beta sources (such as ${ }^{90} \mathrm{Sr} /{ }^{90} \mathrm{Y}$ ) released in the accident [1]. In the previous study [1], the results of EGS5 [2] simulation were in good agreement with the measured results to within $9 \%$ in the range from 1 to $1000 \mu \mathrm{m}$ deep in ICRU tissue. The PHITS [3] code is much easier to use than the EGS5 code, to understand the dose distribution around the source by drawing absorbed dose map using a mesh-tally method. We try to perform benchmark analysis using PHITS code for the evaluation of the absorbed dose for beta radiation.

These dose map using a mesh-tally method can be used for workers to recognized radiation field condition and to avoid an unnecessary dose exposure.

\footnotetext{
*Corresponding author. Email: nobuhara@tokyo-nucl.co.jp
}

\section{Material and methods}

\subsection{Benchmark experiment}

A series of beta source experimental data to measure the absorbed dose rate in ICRU tissue phantom by PTB [4] was used for our benchmark evaluation by the PHITS code.

The measurement system developed by PTB consisted of irradiation devices, a source holder, a source stand, a beam-flattening filter, a phantom, an extrapolation ion chamber and so on. The ionization chambers having a diameter of $3 \mathrm{~cm}$ are set 1-10000 $\mu \mathrm{m}$ deep.

In the reference [5] and ISO 6980-2 [6], the absorbed dose rate at depth $d$ in the ICRU phantom from beta radiation can be approximated by the following fitting function (1).

$$
\begin{array}{r}
T(d)=\frac{\sum_{i=0}^{8}\left(T_{i} \cdot \cos [i \cdot \arccos \{X(d)\}]\right)-\tau_{b r}}{1-\tau_{b r}} \\
\text { With } X(d)=2 \cdot \frac{\log _{10}\left(\frac{d+d_{\text {shift }}}{d_{\text {min }}+d_{\text {shift }}}\right)}{\log _{10}\left(\frac{d_{\text {max }}+d_{\text {shift }}}{d_{\text {min }}+d_{\text {shift }}}\right)}-1
\end{array}
$$

The $d_{\text {min }}, d_{\text {shift }}, d_{\max }, T_{i}(i=0 . .8)$ and $\tau$ br are fitting parameter which was given in reference [5]. 


\subsection{Calculation methods}

The PHITS ver. 2.88 code was used to calculate the absorbed dose. Physics model of PHITS ver. 2.88 has employed original mode (use photon and electron library) and EGS5 mode (PHITS-EGS). We use EGS5 mode to calculate absorbed dose from beta radiation because models recommended from PHITS manual [3] to use electron transport is EGS5 mode.

We modeled the measurement system calculation geometry as much accurately as we could find in PTB reports $[4,5,7,8]$. Figure 1 shows a calculation geometry of ${ }^{90} \mathrm{Sr} /{ }^{90} \mathrm{Y}$ case modeled from the PTB reports. In Table 1 the material used in our calculation is shown. The source intensity, source size, dimensioning of the flattening filter and source window of ${ }^{90} \mathrm{Sr} /{ }^{90} \mathrm{Y}$ source and ${ }^{85} \mathrm{Kr}$ are shown in Table 2. The source holder was not considered in our simulation since the size of the source holder was not described in the PTB reports.

We perform 3 benchmark analyses to evaluate the absorbed dose from beta emitting nuclide to validate 3 condition, the first one is important beta nuclide ${ }^{90} \mathrm{Sr} /{ }^{90} \mathrm{Y}$ with filter and the second one is same beta nuclide ${ }^{90} \mathrm{Sr} /{ }^{90} \mathrm{Y}$ without filter (this is different shielding condition from first one) and the third one is ${ }^{85} \mathrm{Kr}$ (maximum beta energy of this is $0.687 \mathrm{MeV}$, that of ${ }^{90} \mathrm{Y}$ is $2.27 \mathrm{MeV}$ ), which are shown in Table 3 .

In the simulation, beta source spectra given in ICRP Pub. 107 [9] were used for calculation. The beta spectrum were shown in Figure 2. To a comparison, another beta source spectrum data from RADAR decay data [10] was also shown in Figure 2. In the PHITS

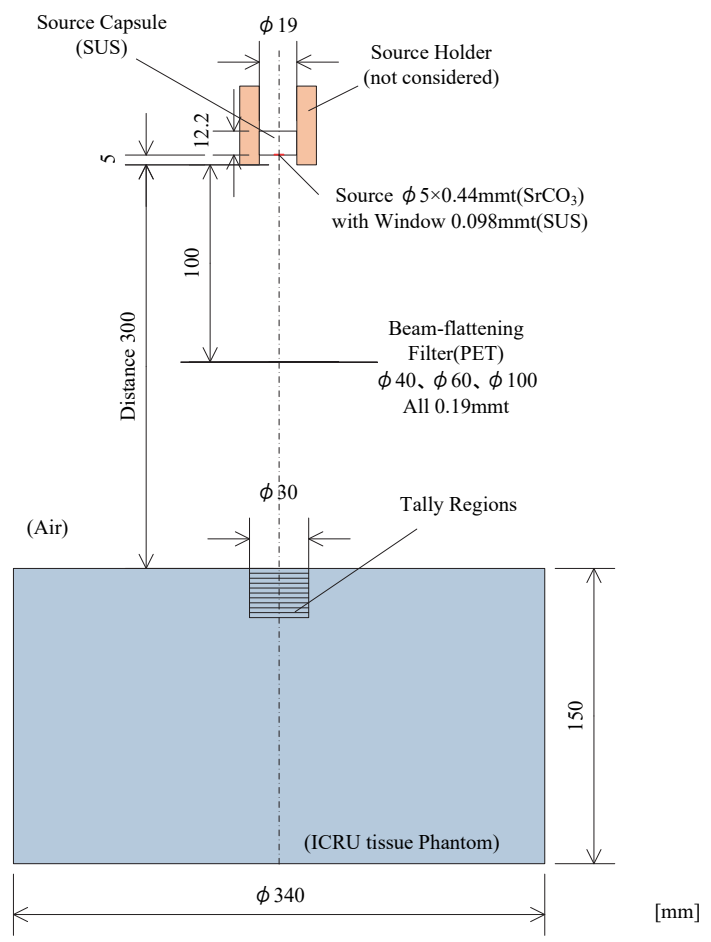

Figure 1. Calculation geometry of benchmark analysis. (Source: ${ }^{90} \mathrm{Sr} /{ }^{90} \mathrm{Y}$, with flattening filter, distance $30 \mathrm{~cm}$ )
Table 1. Density and composition of materials used in the simulation.

\begin{tabular}{|c|c|c|c|c|c|c|}
\hline $\begin{array}{c}\text { Material } \\
\text { Density } \\
\left(\mathrm{g} / \mathrm{cm}^{3}\right)\end{array}$ & Air & $\begin{array}{c}\text { ICRU } \\
\text { tissue }\end{array}$ & PET & SUS & $\mathrm{SrCO}_{3}$ & $\mathrm{Kr}$ \\
\hline \multicolumn{6}{|c|}{ Composition (wt.\%) } & \\
\hline $\mathrm{H}$ & & 10.12 & 4.2 & & & \\
$\mathrm{C}$ & 0.01 & 11.1 & 62.5 & 0.1 & 8.14 & \\
$\mathrm{~N}$ & 75.53 & 2.6 & & & & \\
$\mathrm{O}$ & 23.18 & 76.18 & 33.3 & & 32.51 & \\
$\mathrm{Si}$ & & & & 0.7 & & \\
$\mathrm{Ar}$ & 1.28 & & & & & \\
$\mathrm{Cr}$ & & & & 18 & & \\
$\mathrm{Mn}$ & & & & 1 & & \\
$\mathrm{Fe}$ & & & & 71.2 & & \\
$\mathrm{Ni}$ & & & & 9 & & \\
$\mathrm{Kr}$ & & & & & & 100 \\
$\mathrm{Sr}$ & & & & & 59.35 & \\
\hline
\end{tabular}

Table 2. Beta source parameter and flattening filter size [4].

\begin{tabular}{|c|c|c|}
\hline Nuclide & ${ }^{90} \mathrm{Sr} /{ }^{90} \mathrm{Y}$ & ${ }^{85} \mathrm{Kr}$ \\
\hline $\begin{array}{c}\text { Source } \\
\text { intensity(MBq) }\end{array}$ & 460 & 3700 \\
\hline source size & $\varphi 5 \mathrm{~mm} \times 0.44 \mathrm{mmt}$ & $\varphi 6.3 \mathrm{~mm} \times 6.6 \mathrm{mmt}^{* 1}$ \\
\hline $\begin{array}{c}\text { source window } \\
\left(\mathrm{mg} / \mathrm{cm}^{2}\right)\end{array}$ & $\begin{array}{c}\text { Stainless Steel } \\
(79)\end{array}$ & $\begin{array}{c}\text { Titanium } \\
(11.3)\end{array}$ \\
\hline $\begin{array}{c}\text { Dimensioning } \\
\text { of flattening } \\
\text { filter }\end{array}$ & $\begin{array}{c}3 \text { concentric } \\
\text { all } 190 \mu \mathrm{m} \text { thick, } \\
\phi 40 \mathrm{~mm}, \\
\phi 60 \mathrm{~mm} \text { and } \\
\phi 1000 \mathrm{~mm} \\
\text { in radius }\end{array}$ & $\begin{array}{c}\text { circular foils, } \\
\text { one } 50 \mu \mathrm{mm} \text { thick and } \\
\text { one } 190 \mu \mathrm{mm} \text { thick and } \\
\phi 550 \text { in radius }\end{array}$ \\
\multicolumn{3}{|c|}{$\begin{array}{c}2 \text { concentric } \\
\text { *1: source size is not affect in }{ }^{85} \mathrm{Kr} \text { case } \\
\text { because it is in gas condition. }\end{array}$} \\
\hline
\end{tabular}

calculation, we set stratified tally regions at the source-side surface in the phantom and each of the stratum of tally regions was set to $30 \mathrm{~mm}$ in diameter and the whole thickness for the stratified tally regions is $2 \mathrm{~cm}$. The devided tally regions is $2 \mu \mathrm{m}$ in thickness and we obtained the absorbed dose rate by scoring deposit energy tally [T-Deposit].

In addition, cutoff energy of electrons was $1 \mathrm{keV}$, that of photons was $10 \mathrm{keV}$ (setting value of $1 \mathrm{keV}$ for electrons and $10 \mathrm{keV}$ for photons are PHITS ver. 2.88 default value), and the number of histories to run was set to $1 \times 10^{9}$ so that an error of the evaluation value would become less than $1 \%$ in the range of 1 to $1000 \mu \mathrm{m}$ depth in ICRU tissue. Therefore these calculated value in the range of 1 to $1000 \mu \mathrm{m}$ depth have sufficient accuracy. 
Table 3. Benchmark case list.

\begin{tabular}{|c|c|c|}
\hline Nuclide & $\begin{array}{c}\text { Flattening } \\
\text { filter }\end{array}$ & $\begin{array}{c}\text { Distance from } \\
\text { source holder }(\mathrm{cm})\end{array}$ \\
\hline${ }^{90} \mathrm{Sr} /{ }^{90} \mathrm{Y}$ & with & $30 \mathrm{~cm}$ \\
\hline${ }^{90} \mathrm{Sr} /{ }^{90} \mathrm{Y}$ & with out & $30 \mathrm{~cm}$ \\
\hline${ }^{85} \mathrm{Kr}$ & with & $30 \mathrm{~cm}$ \\
\hline
\end{tabular}

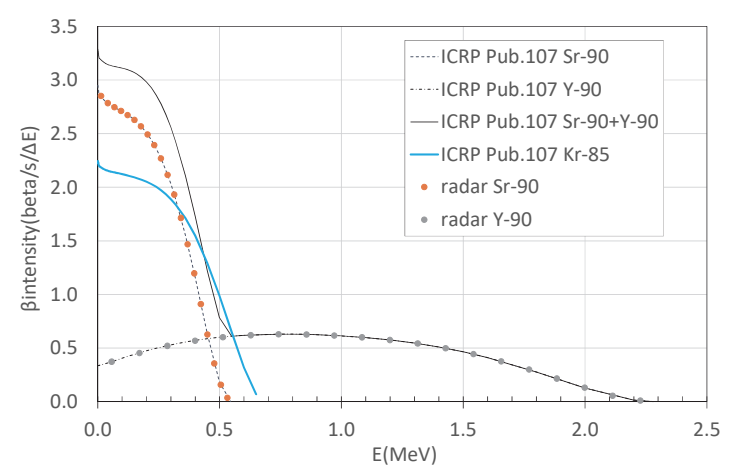

Figure 2. Beta source spectrum $[8,10]$.

\section{Calculation results}

\subsection{Calculation Result for a depth dose distribution}

Figure 3 shows a comparison of the simulated and the measured results of absorbed dose rates for ${ }^{90} \mathrm{Sr} /{ }^{90} \mathrm{Y}$ beta radiation at $30 \mathrm{~cm}$ distance from the source holder with the beam-flattening filter. EGS5 reference value [1] is also showed in this figure. In the comparison for beta radiation, the simulated absorbed dose rates agreed with the measured absorbed dose rates to within 3\% in the range of 1 to $1000 \mu \mathrm{m}$ depth in ICRU tissue. The $\mathrm{C} / \mathrm{M}$ factor (PHITS Calculation / Measurement) is in range 1.00 to 1.02 . The PHITS code showed the same results as EGS5 code.

The absorbed dose distribution from ${ }^{90} \mathrm{Sr} /{ }^{90} \mathrm{Y}$ without flattening filter and ${ }^{85} \mathrm{Kr}$ with flattening filter in the ICRU tissue phantom are shown in Figure 4 and Figure 5.

In the case of ${ }^{90} \mathrm{Sr} /{ }^{90} \mathrm{Y}$ without flattening filter (Figure 4), $\mathrm{C} / \mathrm{M}$ is in range 1.01 to 1.03 . The ratio of maximum absorbed dose in depth to the surface of ICRU tissue phantom for the case without a filter is higher than without filter. In this case, PHITS calculation results exhibits that the depth dose curve is little changed because low beta energy part affect to a phantom. In the case of ${ }^{85} \mathrm{Kr}$ with flattening filter (Figure 5), $\mathrm{C} / \mathrm{M}$ is in the range 1.02 to 1.06 . Table 4 shows the range of $\mathrm{C} / \mathrm{M}$ in the range from 1 to $1000 \mu \mathrm{m}$ deep in ICRU tissue. Although the depths of the absorbed dose in the ICRU tissue depend on the range to electron energies and a filter geometry, the results of calculated absorbed dose are in good agreement with the measured results to within the factor of 1.00 to 1.06 in this study. For a survey meter measurement relative standard deviation in JIS 4333:2006 [11] (as ordinary use for measurement requirement in field) was defined between $-(15 \%+u)$ and $+(15 \%+u)$. Parameter $u$ is relative expanded uncertainty, and u may be almost $5 \%$ in normal usage. The $\mathrm{C} / \mathrm{M}$ of PHITS code calculation are appropriate to this evaluation. The PHITS code showed almost the same results as EGS5 code in this study.

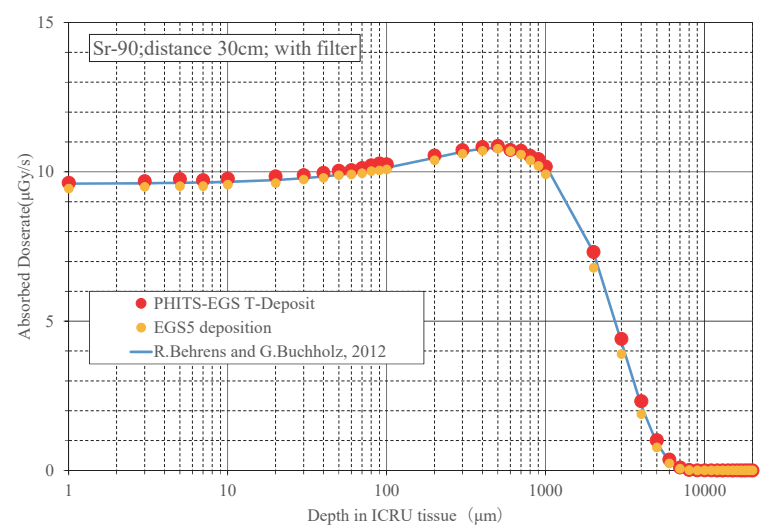

Figure 3. Comparison of simulated and measured depth dose curves (absorbed dose to tissue).

(Source: ${ }^{90} \mathrm{Sr} /{ }^{90} \mathrm{Y}$, with flattening filter, distance $30 \mathrm{~cm}$ )

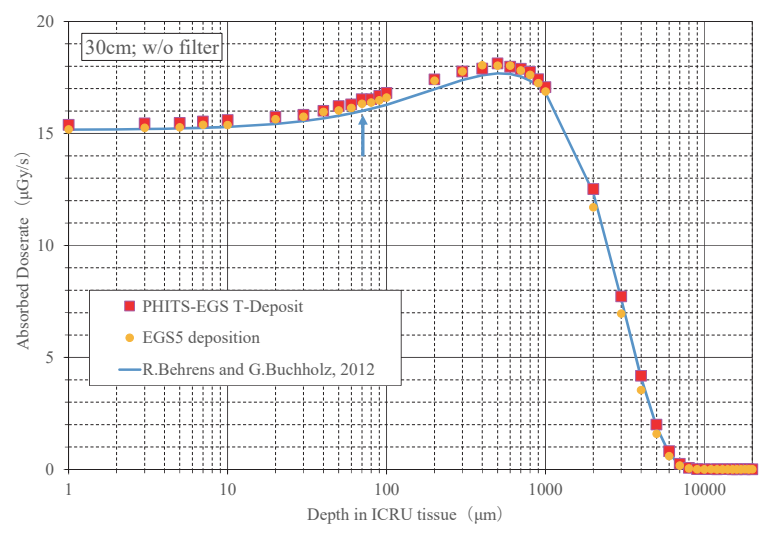

Figure 4. Comparison of simulated and measured depth dose curves (absorbed dose to tissue).

(Source: ${ }^{90} \mathrm{Sr} /{ }^{90} \mathrm{Y}$, without flattening filter, distance $30 \mathrm{~cm}$ )

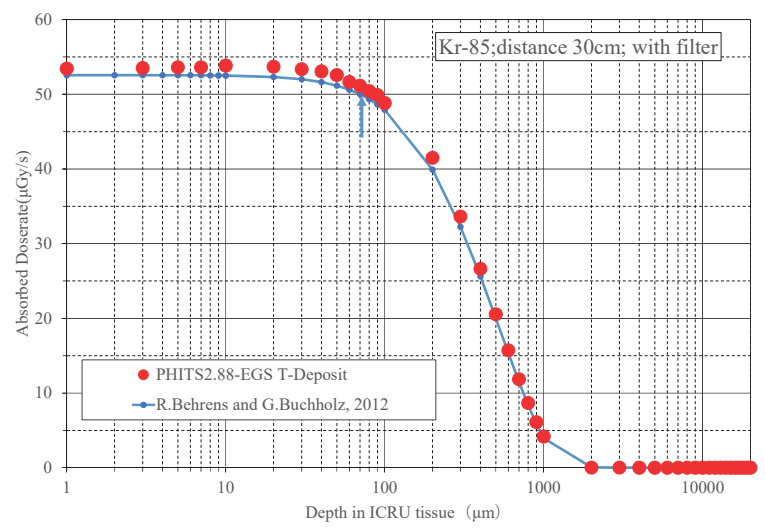

Figure 5. Comparison of simulated and measured depth dose curves (absorbed dose to tissue).

(Source: ${ }^{85} \mathrm{Kr}$, with flattening filter, distance $30 \mathrm{~cm}$ ) 
Table 4. PHITS calculation benchmark result summary.

\begin{tabular}{|c|c|c|}
\hline Nuclide & $\begin{array}{c}\text { Flattening } \\
\text { filter }\end{array}$ & $\begin{array}{c}\mathrm{C} / \mathrm{M} \text { range } \\
(1 \sim 1000 \mu \mathrm{m})\end{array}$ \\
\hline${ }^{90} \mathrm{Sr} /{ }^{90} \mathrm{Y}$ & with & $1.00 \sim 1.02$ \\
\hline${ }^{90} \mathrm{Sr} /{ }^{90} \mathrm{Y}$ & with out & $1.01 \sim 1.03$ \\
\hline${ }^{85} \mathrm{Kr}$ & with & $1.02 \sim 1.06$ \\
\hline
\end{tabular}

\subsection{Calculation Result for a spatial dose distribution}

The spatial distribution of the absorbed dose calculation is shown in Figure 6. In this calculation mesh size is $0.01 \mathrm{~cm}$ to realize absorbed distribution in the phantom. Using this map, we can easily understand the dose map around the structure like a phantom. Figure 7, shows a focusing view of the dose distribution at the front of phantom. The border between a green color and a blue color is perpendicular to the phantom front surface as required in this measurement system for ISO 6980-2. In this situation, we can see plane parallel beam field condition. For real workers case, if a realistic modeling is done, accurately absorbed dose estimation will be obtained. These map can be used for workers to recognized radiation field condition and to avoid an unnecessary dose exposure.

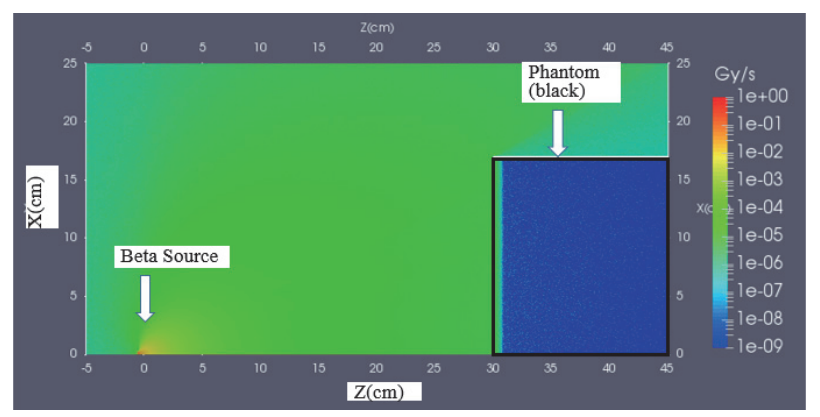

Figure 6. Calculation dose contour MAP.

(Source: ${ }^{90} \mathrm{Sr} /{ }^{90} \mathrm{Y}$, with flattening filter, distance $30 \mathrm{~cm}$ )

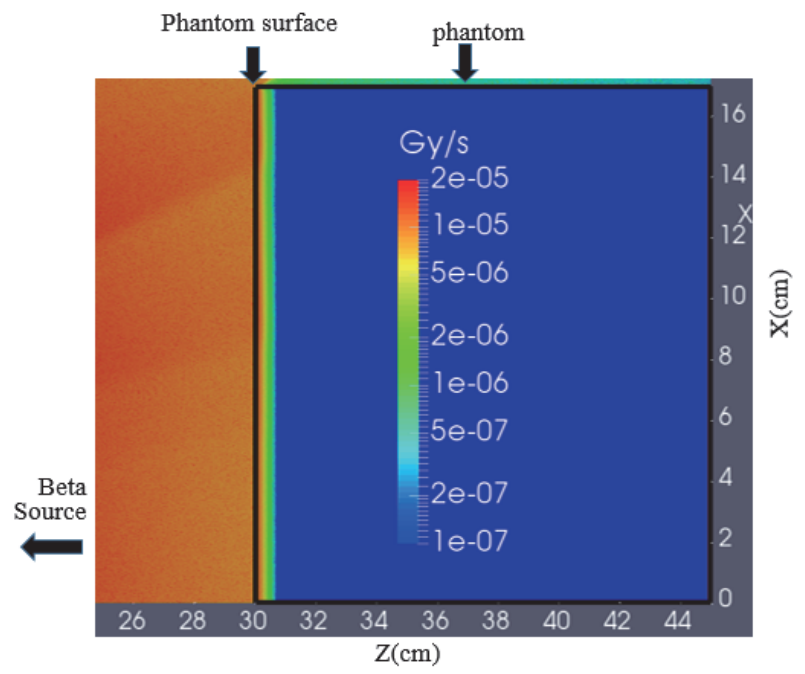

Figure 7. Calculation dose contour MAP focusing on phantom surface.

(Source: ${ }^{90} \mathrm{Sr} /{ }^{90} \mathrm{Y}$, with flattening filter, distance $30 \mathrm{~cm}$ )

\section{Conclusion}

The simulated absorbed dose rates for beta radiation by PHITS agreed with the measured absorbed dose rates to within $6 \%$ in the range from 1 to $1000 \mu \mathrm{m}$ deep in ICRU tissue. The $\mathrm{C} / \mathrm{M}$ of PHIT code calculation are appropriate to this evaluation to compare with measurement requirement of absorbed dose from beta radiation. The PHITS code showed almost the same results as EGS5 code. We can evaluate absorbed dose from beta emitting beta nuclide around the contaminated water tank and around the ground.

The PHITS's ability to visualize with T-Deposit is useful and powerful presentation Dose MAP of beta radiation for a decontamination workers to recognized radiation field condition.

\section{Acknowledgements}

The authors wish to thank Dr. T. Sato for the answer to use PHITS option.

\section{References}

[1] S. Iwai and F. Nobuhara, Benchmark analysis of absorbed dose rate for ${ }^{90} \mathrm{Sr} /{ }^{90} \mathrm{Y}$ beta radiation, Proc. of the 22 EGS Users' Meeting in Japan, KEK Proceedings 2015-6, (2015), p. 38.

[2] H. Hirayama, Y. Namito, A.F. Bielajew, S.J. Wilderman and W.R. Nelson, The EGS5 code system, SLAC-R-730 (2005).

[3] T. Sato, K. Niita, N. Matsuda, S. Hashimoto, Y. Iwamoto, S. Noda, T. Ogawa, H. Iwase, H. Nakashima, T. Fukahori, K. Okumura, T. Kai, S. Chiba, T. Furuta and L. Sihver, Particle and heavy ion transport code system PHITS, Version 2.52, J. Nucl. Sci. Technol. 50 (2013), pp. 913-923.

[4] P. Ambrosi, G. Buchholz and K. Helmstädter, The PTB Beta Secondary Standard BSS2 for radiation protection, JINST, 2 (2007), P11002.

[5] R. Behrens and G. Buchholz, Extensions to the Beta Secondary Standard BSS2, JINST, 6 (2011), P11007.

[6] ISO 6980-2, International Organization for Standardization, Reference beta-particle radiation Part 2: Calibration fundamentals related to basic quantities characterizing the radiation field, (2004).

[7] J. Brunzendorf, Depth-dose curves of the beta reference fields ${ }^{147} \mathrm{Pm},{ }^{85} \mathrm{Kr}$ and ${ }^{90} \mathrm{Sr} /{ }^{90} \mathrm{Y}$ produced by the Beta Secondary Standard BSS2, Radiat. Prot. Dosimetry, 151 (2012), pp. 211-217.

[8] R. Behrens, Simulation of the radiation fields of the Beta Secondary Standard BSS 2, JINST, 8 (2013), P02019.

[9] ICRP Publication 107, Nuclear Decay Data for Dosimetric Calculations Annals of the ICRP, 38 (2008).

[10]RADAR - The Decay Data, URL: http://www. doseinfo-radar.com/RADARDecay.html

[11]JIS 4333:2014, Japanese Industrial Standards Committee, Portable ambient and/or directional dose equivalent (rate) meters and/or monitors for X, gamma and beta radiation. 